\title{
Recuperación de Bienes Arqueológicos desde la Perspectiva del Sistema Jurídico Venezolano: El Caso de la Piedra Sagrada Kueka Abuela
}

Recovery of Archaeological Property from the Perspective of the Venezuelan Legal System: The Case of the Kueka Abuela Sacred Stone

Dra. Sorily Carolina Figuera Vargas, PhD

Profesora Titular PUCE (Facultad de Jurisprudencia). PhD por la Universidad de Salamanca.

Artículo Original (Investigación)

RFJ, No. 1, 2017, pp. 219-228, ISSN 2588-0837

RESUMEN: El documento desarrolla la idea de que la donación que realizó Héctor Hernández Mujica a Alemania, en su condición de presidente de INPARQUES en 1998, violó varias disposiciones legales vigentes en el ámbito nacional e internacional, que protegen al Parque Nacional Canaima, Patrimonio Natural de la Humanidad de la UNESCO desde 1994. Además, evalúa dicha normativa legal, que conforma el sistema de protección del patrimonio cultural y natural de Venezuela.

PALABRAS CLAVE: Recuperación de bienes arqueológicos, sistema jurídico venezolano, derecho internacional privado, protección jurídica, jurisdicción.

ABSTRACT: This paper develops the idea that the donation made by Héctor Hernández Mujica to Germany, in his capacity as president of INPARQUES in 1998, violated several legal provisions in force nationally and internationally, which protect the Canaima National Park, a UNESCO Natural World Heritage Site since 1994. In addition, it evaluates this legal regulation, which forms the system of protection of the cultural and natural heritage of Venezuela.

KEYWORDS: Recovery of archaeological assets, Venezuelan legal system, international private law, legal protection, jurisdiction. 


\section{INTRODUCCIÓN}

En 1998 el creador plástico Wolfang von Schwarzenfeld, ciudadano austriaco-alemán, se trasladó al Parque Nacional Canaima del estado Bolívar de Venezuela para seleccionar dos piedras como parte de una exhibición escultórica en homenaje a la Paz, denominada Global Stone, cuya ubicación estaría en Alemania. En ese contexto, se firmó un acuerdo entre Héctor Hernández Mujica -en aquel entonces presidente de INPARQUES (ente gubernamental responsable de los parques nacionales en Venezuela) - y el Encargado de Negocios de la Embajada de la República Federal Alemana, Hans Peter Pliscka, para la donación de una piedra de jaspe por parte de INPARQUES al pueblo alemán, como aporte a dicho proyecto. Una de estas piedras es conocida con el nombre de "Kueka Abuela" y, cabe aclarar, tiene una gran connotación cosmológica para el pueblo indígena Pemón, habitantes ancestrales de dicho territorio.

Wolfang von Schwarzenfeld a pesar de conocer el descontento del pueblo Pemón y la petición para que no se llevara esta piedra a Alemania, al contar con el beneplácito de las autoridades venezolanas de aquella época, ignoró dicha exigencia, al sacar la piedra de manera fraudulenta del lugar donde los indígenas la habían retenido para que no saliera de su territorio y menos del país. Este "artista" alegó que la roca era arenisca y por ello no podía ser considerada sagrada. Sin embargo, para el pueblo Pemón, el personaje mitológico Kueka ${ }^{6}$ se encuentra dentro de esta piedra de casi 30 toneladas y de 12 metros cúbicos.

Ahora bien, las acciones del actual gobierno venezolano (que comenzó su mandato justo después de este acontecimiento), a través de la Comisión del Ambiente y Ordenación Territorial del extinto Senado, la Procuraduría General de la República, la Cancillería y el Instituto del Patrimonio Cultural, se han enmarcado en declarar la ilicitud de la mencionada donación y de la extracción de la piedra Kueka Abuela ${ }^{67}$.

66 Kueka era un joven Pemón Taure Pam que fue en busca de la joven más bella de la comunidad Macuxi, irrespetando las normas establecidas por Makunaima, dios Pemón celoso y estricto. Luego de casarse, la pareja huyó; pero Makunaima los persiguió, los maldijo y sopló al viento una oración: entonces, Kueka y su esposa fueron convertidos en piedra.

67 Resolución del Ministerio Popular para la Cultura de la República Bolivariana de Venezuela, publicada en la Gaceta Oficial No 39.346, de fecha 14/01/2010. 
En vista de lo antes expuesto, comparto la idea que ciertamente la donación que realizó Héctor Hernández Mujica a Alemania, en su condición de presidente de INPARQUES en 1998, violó varias disposiciones legales vigentes en el ámbito nacional e internacional, que protegen al Parque Nacional Canaima, Patrimonio Natural de la Humanidad de la UNESCO desde 1994. Estudiaremos a continuación dicha normativa legal, que conforma el sistema de protección del patrimonio cultural y natural de Venezuela.

\section{NORMATIVA VENEZOLANA SOBRE PROTECCIÓN DE BIENES CULTURALES Y LA SUSTRACCIÓN DE LA PIEDRA SAGRADA KUEKA ABUELA}

El 15 de marzo de 1999, la Procuraduría General de la República venezolana emitió su opinión sobre el caso, al señalar que la extracción de jaspe es una actividad prohibida en los Parques Nacionales, según lo establecido en los artículos 7 y 8 de la Ley de Minas ${ }^{68}$. Así como en las disposiciones contenidas en el artículo 21 y siguientes de la Ley Orgánica de Hacienda Pública Nacional ${ }^{69}$, que prevé que ningún funcionario público podrá disponer por medio de permisos y autorizaciones de bienes pertenecientes a la República, de lo contrario se le aplicarán las sanciones correspondientes. De igual forma, determinó la Procuraduría que dicha donación fue violatoria a la Ley Orgánica de Ordenación del Territorio ${ }^{70}$, en lo correspondiente a la Administración de Áreas Bajo Régimen de Administración Especial y del Plan de Ordenamiento y Reglamento de Uso de Sector Oriental del Parque Nacional Canaima.

Además, a mi entender, la sustracción arbitraria de esta piedra con valor ancestral para el pueblo indígena Pemón, que forma parte del patrimonio de la República venezolana ${ }^{71}$, se hizo en franca violación del artículo 2 de la Ley de Protección y Defensa del Patrimonio Cultural, que determina:

68 Publicada en la Gaceta Oficial No 36.687 de fecha 26/04/1999.

69 Publicada en la Gaceta Oficial No 39.238 de fecha 10/08/2009.

70 Publicada en la Gaceta Oficial No 3.238 Extraordinario de fecha 11/08/1983.

71 Artículo 6.13 de la Ley de Protección y Defensa del Patrimonio Cultural de Venezuela. Publicada en Gaceta Oficial No 4.623 Extraordinario, de fecha 03/10/1993. 
"La defensa del Patrimonio Cultural de la República es obligación prioritaria del Estado y de la ciudadanía.

Se declara de utilidad pública e interés social la preservación, defensa y salvaguarda de todas las obras, conjuntos y lugares creados por el hombre o de origen natural, que se encuentren en el territorio de la República, y que por su contenido cultural constituyan elementos fundamentales de nuestra identidad nacional".

Al mismo tiempo, se violaron los artículos 3, 4, 9 y 15 del Decreto 1640 del 5 de junio de 1991: Plan de Ordenamiento y Reglamento de uso del Sector Oriental del Parque Nacional Canaima, dictado por el Ejecutivo venezolano, que consagran la prohibición de extraer cualquier recurso que pueda romper los ecosistemas e irrespetar la cultura y creencias de los pobladores originarios.

Es importante que tengamos presente que para autores como Blanc Altemir, la noción de patrimonio común de la humanidad "se proyecta igualmente a otros ámbitos específicos como el cultural (patrimonio arqueológico y artístico) o el natural (especies salvajes y medio ambiente), en lo que se ha llamado "el patrimonio común de la humanidad por afectación”, desde el momento en que la práctica totalidad de este se encuentra bajo competencia estatal, al faltar por lo tanto el elemento fundamental de la exclusión de soberanía" ${ }^{72}$.

\section{NORMATIVA INTERNACIONAL SOBRE PROTECCIÓN DE BIENES CULTURALES Y LA SUSTRACCIÓN DE LA PIEDRA SAGRADA KUEKA ABUELA}

La noción de un patrimonio común de la Humanidad pese a sus innegables ambigüedades, se ha materializado jurídicamente en la práctica internacional; no obstante, sigue siendo un concepto polémico que despierta antagonismos políticos ${ }^{73}$. Asimismo añadiré cómo se establece doctrinalmente que la idea de bien común, la cual alude al patrimonio cultural, tampoco ha desplegado todavía todo su potencial, pero contribuye con el hecho de establecer un sistema de cooperación

72 Blanc Altemir, A. (1992). El patrimonio común de la Humanidad. Hacia un régimen jurídico internacional para su gestión. Editorial Boch.167.

73 Carillo Salcedo, J.A. (1984). El Derecho Internacional en un mundo en cambio. Tecnos. Madrid. 202. 
internacional a través de la difusión, intercambio de información, promoción de la investigación en materia de patrimonio cultural y, especialmente, a través de la asistencia internacional, que contribuye a modificar la idea de reciprocidad tradicionalmente presente en las disposiciones convencionales .

Para Camps, la práctica de los Estados en materia de tratados pone de manifiesto un progresivo incremento de pactos en los cuales se rompe la regla clásica del do ut des. Según dicho principio, el Estado está obligado solo en la medida en que la parte contraria se atiene a la misma obligación o a una obligación que corresponda, por lo que, se encuentra libre de todo vínculo en cuanto la parte contraria viola sus compromisos. Este principio de reciprocidad en materia convencional, que se traduce en un beneficio directo e inmediato para los contratantes, no está presente en dichos tratados, entonces, para el Estado contratante únicamente comportan obligaciones ${ }^{74}$.

Desde el año 2005 la República Bolivariana de Venezuela es parte de la Convención sobre las Medidas que deben Adoptarse para Prohibir e Impedir la Importación, la Exportación y la Transferencia de Propiedad Ilícitas de Bienes Culturales, adoptada en el seno de la UNESCO, en $1970{ }^{75}$. Alemania es parte desde el año 2007.

En la Resolución emitida por el Ministerio Popular para la Cultura de la República Bolivariana de Venezuela, publicada en la Gaceta Oficial No 39.346, de fecha $14 / 01 / 2010$, se establece que la piedra Kueka Abuela o piedra de jaspe, es una roca sagrada para la etnia Pemón, tradicionalmente respetada y custodiada por ese pueblo indígena, la cual constituye un Bien de Interés Cultural de la Nación y la misma fue extraída ilícitamente del Parque Nacional Canaima, hallándose actualmente en el Parque Municipal Tiergarten de la Ciudad de Berlín, Alemania.

De allí que el Estado venezolano ha emprendido medidas administrativas y diplomáticas conducentes a la restitución de esta piedra por parte del Estado alemán. La última respuesta recibida a esta solicitud se dio en el año 2003, cuando el representante del Ministerio de Relaciones Exteriores de Alemania, manifestó la voluntad del gobierno

74 Camps Mirabet, N. (2000). La Protección Internacional del Patrimonio Cultural. Tesis presentada para aspirar al título de Doctora en Derecho en la Universidad de Lleida. Lleida. 39.

75 Publicada en Gaceta Oficial No 5.747, Extraordinario de fecha 23/12/2004. 
alemán de devolver la piedra Kueka Abuela, siempre y cuando el gobierno de Venezuela se hiciera responsable por los gastos de transportes y por las acciones que terceros puedan y quieran ejercer sobre la referida piedra de 30 toneladas y de 12 metros cúbicos.

El Estado venezolano ante la respuesta del Estado alemán, alegó el artículo 7, literal b. ii de la Convención sobre las Medidas que deben Adoptarse para Prohibir e Impedir la Importación, la Exportación y la Transferencia de Propiedad Ilícitas de Bienes Culturales (UNESCO) ${ }^{76}$.

Sobre este punto, considero que Venezuela al alegar el artículo 7 de la Convención de la UNESCO, incurrió en un error de interpretación, pues la disposición claramente advierte que tendrá aplicación en los casos de bienes culturales robados e importados después de la entrada en vigor de la Convención en los dos Estados interesados. Para finalmente determinar que, todos los gastos correspondientes a la restitución del o de los bienes culturales en cuestión, correrán a cargo del Estado requirente. Se observa que la sustracción de la piedra Kueka se realizó en 1998 y la Convención de la UNESCO comenzó a tener vigencia en Venezuela en el año 2005 y en Alemania en al año 2007.

No obstante, el artículo 7 de la Convención de la UNESCO fue alegado por Venezuela en la Resolución del Ministerio Popular para la Cultura, de fecha 14/01/2010. El Estado venezolano asumió entonces que reconoce la existencia de los pueblos y comunidades indígenas. Por tanto, obligado a respetar el derecho que estos pueblos tienen a mantener y desarrollar su identidad étnica y cultural, cosmovisión, valores, espiritualidad y sus lugares sagrados de culto, y en el caso particular, el derecho del pueblo Pemón a venerar su "piedra Kueka Abuela", resolvió solicitar al Ministerio del Poder Popular para las Relaciones Exteriores, por intermedio del Ministerio del Poder Popular para la Cultura, todas las diligencias que sean necesarias ante el gobierno de la República Federal de Alemania, para concretar la restitución y retorno efectivo de la piedra Kueka Abuela a su lugar originario ${ }^{77}$.

Es importante agregar que el Estado venezolano desde 1990 forma parte de la Convención sobre la Protección del Patrimonio Mundial

76 Resolución del Ministerio Popular para la Cultura de la República Bolivariana de Venezuela, publicada en la Gaceta Oficial No 39.346, de fecha 14/01/2010.

77 Resolución del Ministerio Popular para la Cultura de la República Bolivariana de Venezuela, publicada en la Gaceta Oficial No 39.346, de fecha 14/01/2010. 
Cultural y Natural, adoptada en el seno de la UNESCO en $19722^{78}$. Esta Convención prevé un sistema de protección y asistencia internacional; sin embargo, "no establece ningún sistema de gestión internacional directa del patrimonio cultural dado que el régimen acordado se basa en el respeto de la soberanía de los Estados, el reconocimiento de los regímenes de propiedad establecidos por las legislaciones nacionales y el suministro de ayuda internacional está basado en el acuerdo con los Estados beneficiarios" 79 .

Alemania ratificó la Convención sobre la Protección del Patrimonio Mundial Cultural y Natural de la UNESCO en 1976, por lo que resulta oportuno citar su artículo 6:

“1. Respetando plenamente la soberanía de los Estados en cuyos territorios se encuentre el patrimonio cultural y natural a que se refieren los artículos 1 y 2 y sin perjuicio de los derechos reales previstos por la legislación nacional sobre ese patrimonio, los Estados Partes en la presente Convención reconocen que constituye un patrimonio universal en cuya protección la comunidad internacional entera tiene el deber de cooperar.

2. Los Estados Partes se obligan, en consecuencia y de conformidad con lo dispuesto en la presente Convención, a prestar su concurso para identificar, proteger, conservar y revalorizar el patrimonio cultural y natural que trata el artículo 11, párrafos 2 y 4 , si lo pide el Estado en cuyo territorio esté situado.

3. Cada uno de los Estados Partes en la presente Convención se obliga a no tomar deliberadamente ninguna medida que pueda causar daño, directa o indirectamente, al patrimonio cultural y natural que tratan los artículos 1 y 2 situado en el territorio de otros Estados Partes en esta Convención" ${ }^{80}$.

78 Publicada en la Gaceta Oficial No 4.191 Extraordinario, de fecha 06/07/1990.

79 Casanovas y La Rosa, O. (1993). La protección internacional del patrimonio cultural, en: AHLADI, Vol. 10. 69 - 70.

80 Publicada en la Gaceta Oficial No 4.191 Extraordinario, de fecha 06/07/1990. 


\section{CONCLUSIÓN}

Venezuela como Estado requirente asumió los gastos correspondientes a la restitución de piedra Kueka Abuela a su territorio, concretamente al Parque Nacional Canaima. Hasta la presente fecha, la piedra en cuestión sigue en el Parque Municipal Tiergarten en Berlín y el pueblo Pemón sigue a la espera que se verifique su restitución.

Finalmente, señalaré que la República Bolivariana de Venezuela no forma parte de la Convención sobre la Defensa del Patrimonio Arqueológico, Histórico y Artístico de las Naciones Americanas ${ }^{81}$, conocida como la Convención de San Salvador de 1976. Ni tampoco forma parte del Convenio de UNIDROIT sobre los Bienes Culturales Robados o Exportados Ilícitamente de 1995.

\section{REFERENCIAS BIBLIOGRÁFICAS}

Blanc Altemir, A. (1992). El patrimonio común de la Humanidad. Hacia un régimen jurídico internacional para su gestión. Editorial Boch.167.

Camps Mirabet, N. (2000). La Protección Internacional del Patrimonio Cultural. Tesis presentada para aspirar al título de Doctora en Derecho en la Universidad de Lleida. Lleida. 39.

Carrillo Salcedo, J. A. (1984). El Derecho Internacional en un mundo en cambio. Tecnos. Madrid. 202.

Casanovas Y La Rosa, O. (1993). La protección internacional del patrimonio cultural. AHLADI, Vol. 10. 69 - 70.

\section{Base Legal}

Artículo 6.13 de la Ley de Protección y Defensa del Patrimonio Cultural de Venezuela. (03/10/1993). Publicada en Gaceta Oficial N. ${ }^{\circ}$ 4.623. Extraordinario.

81 Aprobada el 16 de julio de 1976 en el sexto periodo ordinario de sesiones de la Asamblea General de la Organización de los Estados Americanos, en Santiago de Chile por Resolución AG/RES-210 (vi-0176). 
Convención sobre la Defensa del Patrimonio Arqueológico, Histórico y Artístico de las Naciones Americanas. Aprobada el 16 de julio de 1976 en el sexto periodo ordinario de sesiones de la Asamblea General de la Organización de los Estados Americanos, en Santiago de Chile por Resolución AG/RES-210 (vi-0176).

Ley de Minas. (26/04/1999). Publicada en la Gaceta Oficial N. ${ }^{\circ}$ 36.687 .

Ley Orgánica de Hacienda Pública Nacional. (10/08/2009). Publicada en la Gaceta Oficial N. ${ }^{\circ} 39.238$.

Ley Orgánica de Ordenación del Territorio. (11/08/1983). Publicada en la Gaceta Oficial N. ${ }^{0} 3.238$. Extraordinario.

Resolución del Ministerio Popular para la Cultura de la República Bolivariana de Venezuela. (14/01/2010). Publicada en la Gaceta Oficial N. ${ }^{\circ} 39.346$.

Resolución del Ministerio Popular para la Cultura de la República Bolivariana de Venezuela. (14/01/2010). Publicada en la Gaceta Oficial N. ${ }^{\circ} 39.346$.

Resolución del Ministerio Popular para la Cultura de la República Bolivariana de Venezuela. (14/01/2010). Publicada en la Gaceta Oficial N. ${ }^{\circ} 39.346$.

UNESCO. (1970). Convención sobre las Medidas que deben Adoptarse para Prohibir e Impedir la Importación, la Exportación y la Transferencia de Propiedad Ilícitas de Bienes Culturales. Publicada en Gaceta Oficial N. ${ }^{\circ}$ 5.747. Extraordinario. De fecha 23/12/2004.

UNESCO. (1972). Convención sobre la Protección del Patrimonio Mundial Cultural y Natural. Publicada en la Gaceta Oficial N. ${ }^{\circ}$ 4.191. Extraordinario. De fecha 06/07/1990. 
Recibido: $14 / 01 / 2017$

Aprobado para publicación: 28/05/2017

Sorily Carolina Figuera Vargas (LLB, LLM, PhD): Es Doctora por la Universidad de Salamanca, Magíster en Derecho Internacional y Relaciones Internacionales por la Universidad Complutense de Madrid, Magíster en Derecho Internacional Privado y Comparado por la Universidad Central de Venezuela, Abogada por la Universidad Bicentenaria de Aragua de Venezuela y Licenciada en Derecho en España. La Dra. Figuera es miembro del Ilustre Colegio de Abogados de Madrid En la actualidad se desempeña como docente titular (TC) de la PUCE.

Correo electrónico: SFIGUERA425@puce.edu.ec 